
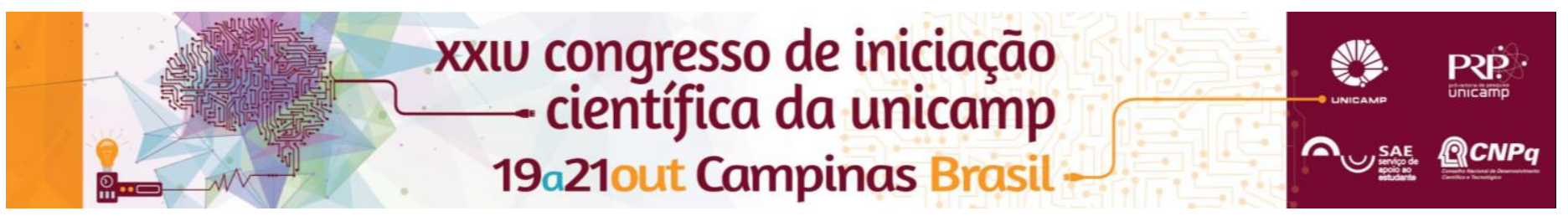

\title{
Síntese e Estudo do Equilíbrio de Fases de líquidos lônicos Próticos
}

\author{
Thamíres Coelho*, Ariel A. T. Hijo, Mariana C. Costa
}

\section{Resumo}

Líquidos iônicos são sais químicos formados por um ânion e um cátion que, por convenção, possuem ponto de fusão inferior a $100^{\circ} \mathrm{C}$, e podem permanecer no estado líquido em uma ampla faixa de temperatura. As suas propriedades os transformam em produtos de interesse industrial devido a seu potencial de aplicação na formulação de produtos e otimização de processos. Este trabalho teve por objetivo estudar a síntese e caracterização do comportamento de fases sólido-líquido da mistura binária de dois líquidos iônicos formados pela mistura de etanolaminas e ácidos graxos. A determinação do diagrama de fases sólido-líquido da mistura binária será realizada utilizando o método da calorimetria exploratória diferencial (DSC). O perfil de fusão dos cristais líquidos iônicos será determinado com o auxilio de microscopia óptica de luz polarizada.

\section{Palavras-chave}

Líquido iônico prótico, microscopia optica, Equilíbrio sólido-líquido.

\section{Introdução}

Ácidos graxos são os principais componentes dos óleos e gorduras. A dietanolamina pode ser considerado tanto uma amina secundária quanto um diálcool e atua como uma base fraca. A mistura de amobos pode gerar líquidos iônicos que são sais com temperatura de fusão inferior a $100^{\circ} \mathrm{C}$ e em geral, são formados pelo menos por um cátion orgânico e um ânion inorgânico. Devido suas propriedades se destacam na química verde como componentes renováveis para solventes orgânicos. Nos últimos anos os Lls têm sido utilizados na otimização de processos de extração de compostos ativos, produção de biomassa e desenvolvimento de cosméticos, detergentes e fármacos ${ }^{1}$.

\section{Resultados e Discussão}

A amostras homogeneizadas em agitador magnético com aquecimento de quantidades previamente conhecidas de ácido mirístico ou palmítico com a dietanolamina. Cada frasco com amostra foi imerso dentro de um béquer contendo fluido térmico que faz com que o aquecimento ocorra igualmente e de forma controlada para evitar a degradação das amostras.

As imagens que são apresentadas nesta seção foram obtidas através de um varrimento de temperaturas feito no microscópio óptico.

Na Figura $1 \mathrm{~A}$ pode-se observar os cristais da amostra em cores vivas cercados por uma pequena quantidade de líquido caracterizado pela cor preta. Com o aumento da temperatura, Figura 1B, a quantidade de sólido diminui, mas nota-se que ainda existem cristais na amostra. Na faixa de temperatura estudada não se chegou a observar a fusão total da amostra, evento que seria caracterizado por uma imagem totalmente preta. Além disso na Figura 1C pode-se observar a existência da cruz de malta que é uma das formas texturais que caracteriza uma mesofase (MAXIMO et al, 2014 b). A cruz de malta confirma a o estado líquido cristalino do sistema ácido mirístico + dietanolamina.
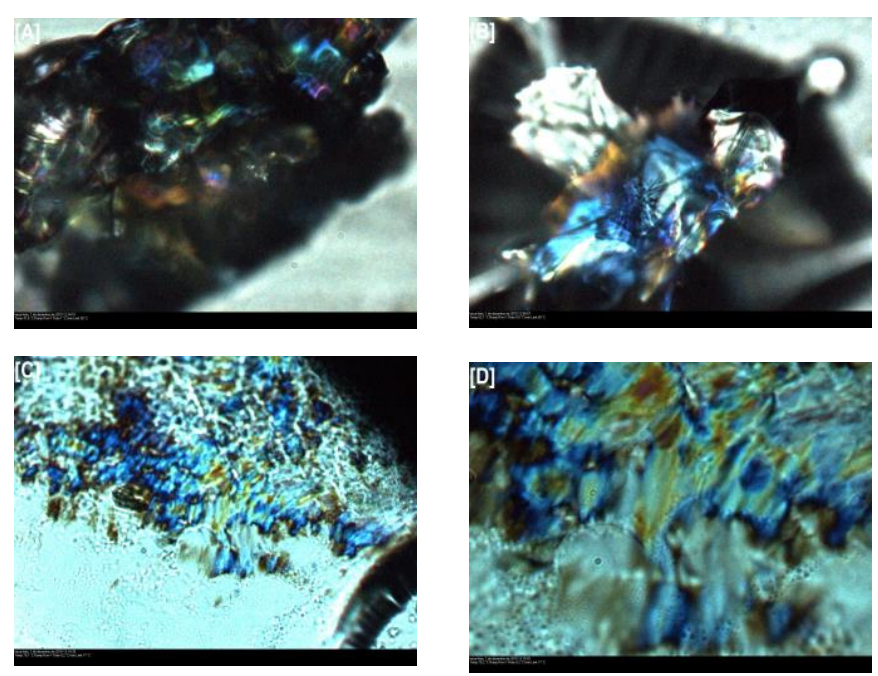

Figura 1. Micrografias ópticas de luz polarizada para amostra ácido mirístico + dietanolamina para $\mathrm{x}_{\text {ácido mirístico }}=0,5:[\mathrm{A}] \mathrm{T}=$ $314,75 \mathrm{~K} ;[\mathrm{B}] ; \mathrm{T}=335,25 \mathrm{~K} ;[\mathrm{C}] \mathrm{T}=343,25 \mathrm{~K} ;[\mathrm{D}] ; \mathrm{T}=$ 343,35 K..

\section{Conclusões}

Com base nos resultados das micrografias das amostras de ácido palmítico + dietanolamina e ácido mirístico + dietanolamina e nos estudos prévios realizados para a elaboração das amostras, é possível afirmar que cristal líquido é formado nesses sistemas e que quanto maior o número de carbono do ácido graxo que compõe o sistema com a dietanolamina maior a temperatura necessária para que os cristais líquidos desapareçam e toda a amostra se torne líquida por completa.

\section{Agradecimentos}

Os autores são gratos à FAPESP, CNPq e FAEPEX UNICAMP.

\footnotetext{
${ }^{1}$ SILVA, D. H. Síntese de Cristais Líquidos iônicos e/ou discóticos contendo os heterociclos 1,2,4 e 1,3,4 oxadiazol. 2013. 131. Categoria (dissertação de Mestrado) Universidade Federal de Santa Catarina, Florianópolis.
} 